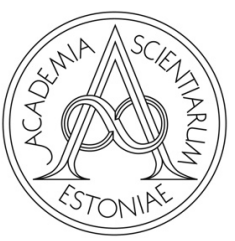

Proceedings of the Estonian Academy of Sciences,

2022, 71, 1, 16-29

https://doi.org/10.3176/proc.2022.1.02

Available online at www.eap.ee/proceedings

STRUCTURAL ENGINEERING

\title{
Quantification of cracks in beams on the Pasternak foundation using Haar wavelets and machine learning
}

\author{
This article is dedicated to Professor Ülo Lepik, the outstanding scientist and great person
}

Helle Hein* and Ljubov Jaanuska

Institute of Computer Science, University of Tartu, Narva mnt 18, 51009 Tartu, Estonia

Received 8 July 2021, accepted 20 October 2021, available online 31 January 2022

(C) 2022 Authors. This is an Open Access article distributed under the terms and conditions of the Creative Commons Attribution 4.0 International License CC BY 4.0 (http://creativecommons.org/licenses/by/4.0).

\begin{abstract}
The inverse problem of crack identification, localisation and severity quantification is addressed in this article. The open cracks are simulated numerically in a homogeneous Euler-Bernoulli beam. The beam rests on the Pasternak foundation. Under the assumption that the size of the crack is small compared to the height of the beam, it is shown that the problem can be solved in terms of crack-induced changes in the natural frequencies or mode shapes. Predictions of the crack characteristics (location and severity) are made by artificial neural networks or random forests. The dimensionless natural frequency parameters or the first mode shape transformed into the Haar wavelet coefficients are used at the inputs of the machine learning methods. The numerical examples indicate that the combined approach of the natural frequencies, Haar wavelets, and machine learning produces accurate predictions. The results presented in the article can help in understanding the behaviour of more complex structures under similar conditions and provide apparent influence on the design of beams.
\end{abstract}

Key words: open cracks, Euler-Bernoulli beam, Pasternak foundation, Haar wavelets, neural network, random forest.

\section{INTRODUCTION}

The soil-structure interaction has broad practical application in engineering, such as the construction of pipelines, road surfaces, or building foundations. Some of the problems, for example, contact pressure distribution or buckling, can be idealised and solved by modelling a beam on an elastic foundation.

There are various models of beams on the elastic foundation described in the literature:Winkler, Pasternak, Vlasov, Filonenko-Borodich, Leontiev models; however, the first two models are widely used in engineering for their simplicity. In the Winkler one-parameter model, the foundation is composed of infinitely close elastic springs which are independent of each other; the vertical surface displacement of the beam is assumed to be proportional to the contact pressure at any point. The Pasternak two-parameter model represents a system of closely placed elastic springs coupled to each other with the elements which transmit the shear force proportional to the slope of the foundation surface [7]. The Pasternak foundation model is used in several soil-structure interactions, e.g. road pavement, rigid concrete pavement for highways and airports,

\footnotetext{
*Corresponding author, helle.hein@ut.ee
} 
a bridge resting on elastomeric bearings, or excavation retaining walls and tunnels in the soil. The present study focuses on the beam on the Pasternak foundation.

During the manufacturing or the structural service period of a beam, some defects or damage can occur. According to Chen et al. [8], the crack is not only the most common defect in structures but also one of the hardest to control. Since the presence of a crack in beams poses an apparent threat to the whole construction, the identification of cracks is of great significance to the safe and reliable operation of the structure and in scheduling maintenance procedures.

Visual or localised experimental methods, such as magnetic field methods, radiography, or thermal field methods, require the structural element of the inspection to be readily accessible. The requirement cannot always be met if the structure is complex and the element is mounted.

A promising alternative to the existing damage identification methods can be found in the modal analysis. It is based on the principle that a reduction in the structural stiffness produces changes in the dynamic characteristics of the structure, such as natural frequencies, mode shapes, and damping ratios [14]. Constant monitoring for the changes in the dynamic response with a small number of sensors helps early detect, localise and estimate severity $[12,21,41]$. However, it is noted that the natural frequencies can only follow the damage severity, but damage locations do not influence the frequencies much; the modal assurance criterion is, in contrast, less sensitive to damage compared with the natural frequencies; the coordinate modal assurance criterion can localise damage in the beams but cannot follow severity [31]. Therefore, Wang [44] recommends incorporating the structural properties with modern numerical methods for accurate crack identification.

A large number of numerical solutions are based on mesh methods, such as the finite element method (FEM) [33,42], the finite difference method [3], the spectral finite element method [24], the differential quadrature method [28], etc. Nevertheless, the FEM may provide accurate dynamic characteristics of a structure if the wavelength is large compared to the mesh size. Furthermore, the FEM becomes increasingly inaccurate as the frequency increases [2]. Other deficiencies of the FEM are related to the mesh definition, calculation, and computer storage.

The statistical methods, such as correlation functions and coefficients, autoregressive models, machine learning methods, properly address the modern-type vibration-based methods. The description of each method can be found in a great number of articles, for example, [19,32,43,46]. Mahmoud and Kiefa [25] investigated a steel cantilever beam with a single edge crack. They used the general regression neural networks (GRNN) and the first six natural frequencies in order to predict the crack size and location. The natural frequencies were calculated using the M-matrix technique and the Newton-Raphson method. Mahmoud and Kiefa drew several important conclusions: the first two natural frequencies were not sufficient to predict the depth and location of a crack since the natural frequencies varied in a cyclic manner; if the crack depth was small $(a / h<0.2)$, it was difficult to quantify since the change in the natural frequencies was small. Hakim et al. [13] applied artificial neural networks (ANNs) to detect cracks in I-beams, particularly the locations of two cracks and their depths. For the training of the ANNs, 52 patterns of 3D finite element simulations and 52 experimentally obtained patterns were used. Each pattern contained the first natural frequency and 14 mode shape values of the first mode at the points on the centreline of the beam, except for the points at the ends. The optimal feed-forward back propagation ANN had the architecture of 15-8-4-3 (all together 179 weights). The mean square error of the test was 0.00449 . The correlation coefficient for the crack severity and two locations of the cracks were $0.9925,0.9680$ and 0.9700 , respectively. Later, Hakim et al. improved the results using an ensemble of five ANNs. Each individual ANN with the architecture of 15-8-4-3 was trained with the data obtained from one of the first five natural frequencies and their mode shape values. The mean square error was 0.0037. The correlation coefficient for the crack severity and two locations of the cracks were $0.9898,0.9856$ and 0.9855 , respectively. It was also concluded that crack localisation was a harder task than the identification of the crack depth.

Although the statistical methods overcome the drawbacks of common non-destructive testing techniques by the ability to extract information from raw data, some issues need to be discussed and resolved. Firstly, the choice of a proper statistical method for the crack quantification in beams is complicated: no systematic 
comprehensive overview or comparison between the performances of different methods has been made thus far. Secondly, in engineering, data are often the result of expensive experiments and will be in short supply; in this case, the only way to ensure generalisation is to restrict the number of weights in the network [45]. Thirdly, an optimal feature vector selection for the data-driven methods can be challenging. The vector is frequently dependent on the structure, the goal of the investigation, the nature of the raw data, advantages and disadvantages of the classifier.

Merging data-driven machine learning methods with the modal analysis, the present article proposes a new theoretical approach to crack quantification. Namely, to overcome the limitations of the modal data and increase the accuracy of predictive models, a search for an informative feature vector is conducted in the field of wavelets. The wavelet analysis represents a modern-type windowing technique for signal decomposition into logarithmically scaled regions [30]. A different view of data (signal) reveals aspects of data that other signal analysis techniques miss [29]. For example, Quek et al. [35] conducted a sensitivity analysis of crack detection in simply supported and clamped beams under a static load. The authors established that the wavelets were sensitive to the curvature of the deflection profile calculated with the aid of the FEM. Using the vibration data and the Haar/Gabor wavelets, multiple cracks were detected. Notably, the Haar wavelets exhibited superior performance for detecting discrete cracks whose depth ratio to the length of the beam was as low as $1 / 150$. The observation of the wavelet sensitivity to the non-linear structure changes was confirmed experimentally by Rucka and Wilde in [38,39].

Although the application of wavelets in structural health monitoring is on the rise, it still requires additional research. Hereof, one of the main questions of the present research is whether the mode shape decomposition by wavelets produces informative data and whether the wavelet coefficients are more informative than natural frequencies. The results are validated using two of the most popular machine learning methods: the ANNs and the random forests (RFs). The numerical examples are conducted on the cracked Euler-Bernoulli beam on the Pasternak foundation.

\section{DYNAMIC RESPONSE OF VIBRATING BEAMS WITH MULTIPLE CRACKS}

In Fig. 1, a clamped Euler-Bernoulli beam of length $L$ is placed on the Pasternak foundation. The beam has $n$ cracks.

According to Rizos et al. [36], Shifrin and Ruotolo [40], a beam with $n$ cracks can be modelled as a beam divided into $n+1$ sections connected by elastic springs. The differential equation of the transverse vibration in each region $x \in\left[x_{i}, x_{i+1}\right]$ of the beam placed is as follows [10]:

$$
E I \frac{\partial^{4} y_{i}(x, t)}{\partial x^{4}}-G_{2} \frac{\partial^{2} y_{i}(x, t)}{\partial x^{2}}+G_{1} y_{i}(x, t)+\rho A \frac{\partial^{2} y_{i}(x, t)}{\partial t^{2}}=0,
$$

where $G_{1}$ is the Winkler foundation modulus, $G_{2}$ denotes the shear modulus of the Pasternak foundation, $i$ represents the number of the section $(i=1, \ldots, n+1)$ and $y_{i}(x, t)$ is the transverse deflection in the $i$-th section. The solution to (1) is sought using the method of separation of variables [20]:

$$
y(x, t)=W(x) T(t) .
$$

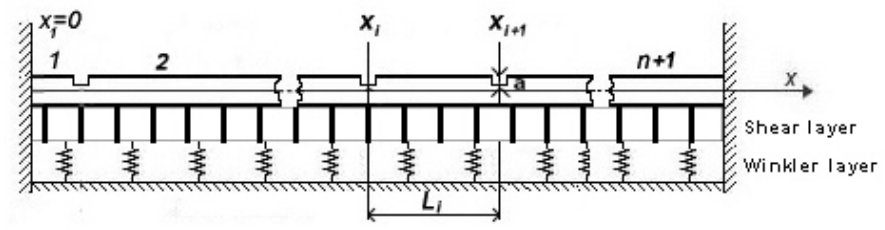

Fig. 1. A clamped beam on the Pasternak foundation. 
Substituting (2) into (1), the equation of the transverse vibration (1) takes the form of

$$
\frac{d^{4} W_{i}(x)}{d x^{4}}-\mu \frac{d^{2} W_{i}(x)}{d x^{2}}+(\gamma-\widetilde{k}) W_{i}(x)=0
$$

where

$$
\mu=\frac{G_{2}}{E I}, \gamma=\frac{G_{1}}{E I}, \widetilde{k}=\frac{m \omega_{*}^{2}}{E I} .
$$

The characteristic equation of (3) can be presented as follows:

$$
\lambda^{4}-\mu \lambda^{2}+(\gamma-\widetilde{k})=0
$$

and the general solution to (3) for the present vibration problem can be presented as follows [37]:

$$
W_{i}=C_{1, i} e^{\lambda_{1} x}+C_{2, i} e^{\lambda_{2} x}+C_{3, i} e^{\lambda_{3} x}+C_{4, i} e^{\lambda_{4} x},
$$

where $\lambda_{1}, \ldots, \lambda_{4}$ are the roots of (5) and $C_{1, i}, \ldots, C_{4, i}$ refer to the integration constants. The equation (3) should be solved separately for each beam section $i(i=1, \ldots, n+1)$. The solution for the whole beam can be put together taking into account the continuity and boundary conditions. The continuity conditions at the crack position $x_{i}$ can be expressed as follows [9]:

$$
\begin{aligned}
W_{i}\left(x_{i}\right) & =W_{i+1}\left(x_{i}\right), \\
\frac{d^{2} W_{i}\left(x_{i}\right)}{d x^{2}} & =\frac{d^{2} W_{i+1}\left(x_{i}\right)}{d x^{2}}, \\
\frac{d^{3} W_{i}\left(x_{i}\right)}{d x^{3}} & =\frac{d^{3} W_{i+1}\left(x_{i}\right)}{d x^{3}}, \\
\frac{d W_{i}\left(x_{i}\right)}{d x}+c_{i} \frac{d^{2} W_{i}\left(x_{i}\right)}{d x^{2}} & =\frac{d W_{i+1}\left(x_{i}\right)}{d x}, i=1, \ldots, n,
\end{aligned}
$$

where $c_{i}$ is the bending constant of the spring:

$$
c_{i}=5.346 \frac{h}{E I} J\left(\eta_{i}\right), \eta_{i}=\frac{a_{i}}{h} .
$$

In (8), $h$ is the height of the beam, $a_{i}$ represents the crack depth and $J\left(\eta_{i}\right)$ denotes the dimensionless local compliance function:

$$
\begin{aligned}
J\left(\eta_{i}\right) & =1.8624\left(\eta_{i}\right)^{2}-3.95\left(\eta_{i}\right)^{3}+16.375\left(\eta_{i}\right)^{4}-37.226\left(\eta_{i}\right)^{5}+76.81\left(\eta_{i}\right)^{6}-126.9\left(\eta_{i}\right)^{7} \\
& +172\left(\eta_{i}\right)^{8}-143.97\left(\eta_{i}\right)^{9}+66.56\left(\eta_{i}\right)^{10}
\end{aligned}
$$

In the case of a clamped-pinned beam, the boundary conditions can be presented as follows:

$$
\begin{gathered}
W_{1}(0)=\frac{d W_{1}(0)}{d x}=0, \\
W_{n+1}(L)=\frac{d^{2} W_{n+1}(L)}{d x^{2}}=0 .
\end{gathered}
$$

The system (3)-(10) can be solved with the aid of exact solution (6) taking into account (7)-(10) or using the Haar wavelet technique $[4,23,26,34]$. 


\section{HAAR WAVELETS}

In recent years, the wavelet transform has occasionally been implemented in structural health monitoring. The advantage of the technique consists in the fact that the method does not require the analysis of the complete structure and has the ability to reveal some hidden parts of data that other signal analysis techniques fail to detect [35,47]. In [22], Lepik demonstrated that the Haar wavelets can be applied for numerical solving of differential equations. Later, many authors showed that the Haar wavelet method can be applied to solving integral and integro-differential equations, e.g. Aziz and Pervaiz [4,34].

The main properties of the Haar wavelet are orthogonality and compact support. The scaling function for the family of the Haar wavelets is symmetric and discontinuous. It resembles a step function which is defined as [5]:

$$
h_{1}(\xi)=\left\{\begin{array}{lc}
1, & \text { for } \xi \in[0,1) \\
0, & \text { elsewhere }
\end{array}\right.
$$

The mother wavelet for the Haar wavelet family is antisymmetric, and it is defined as:

$$
h_{2}(\xi)=\left\{\begin{array}{lc}
1, & \text { for } \xi \in\left[0, \frac{1}{2}\right), \\
-1, & \text { for } \xi \in\left[\frac{1}{2}, 1\right) \\
0, & \text { elsewhere }
\end{array}\right.
$$

All the other functions in the Haar wavelet family are defined on the subintervals of $[0,1]$. The daughter functions are generated from the mother wavelet $h_{2}(\xi)$ by scaling and shifting it along the abscissa [23]:

$$
h_{i}(\xi)=\left\{\begin{array}{lc}
1, & \text { for } \xi \in\left[\xi^{(1)}, \xi^{(2)}\right), \\
-1, & \text { for } \xi \in\left[\xi^{(2)}, \xi^{(3)}\right), \\
0, & \text { elsewhere, }
\end{array}\right.
$$

where

$$
\xi^{(1)}=\frac{k}{m}, \xi^{(2)}=\frac{k+0.5}{m}, \xi^{(3)}=\frac{k+1}{m} .
$$

Integer $k$ is the translational parameter or the shifting factor $(k=0,1, \ldots, m-1), m$ denotes the dilatation parameter or the factor of scale $\left(m=2^{j}\right.$ and $\left.j=0,1, \ldots, J\right), j$ indicates the level of the wavelet. Integer $J$ is the maximal level of resolution and $M$ represents the resolution coefficient $\left(M=2^{J}\right)$. The relation between $i, m$ and $k$ is expressed as $i=m+k+1$.

Generally, wavelet transform is capable of providing the time and frequency information simultaneously. Several techniques are described in [1,23]. In this article, the collocation points method [23] is used since it is applicable to the mode shape representation in the form of a limited feature matrix vector. The values of the collocation points are defined by [23]:

$$
\xi_{l}=\frac{l-0.5}{2^{J+1}}=\frac{l-0.5}{2 M},
$$

where $l=1,2, \ldots, 2 M$. The collocation points divide the interval $\xi \in[0,1)$ into $2 M$ parts; each part is of length $\triangle \xi=1 /(2 M)$.

The wavelet function values of (13) in the collocation points are presented in the Haar matrix $H$, whose dimensions are $2 M \times 2 M$. The elements of the matrix are $H_{2 M \times 2 M}(i, l)=h_{i}\left(\xi_{l}\right)$. An example of the Haar matrix for $M=2$ is presented below: 


$$
H_{4 \times 4}=\begin{gathered}
h_{1} \\
h_{2} \\
h_{3} \\
h_{4}
\end{gathered}\left(\begin{array}{cccc}
\frac{1}{8} & \frac{3}{8} & \frac{5}{8} & \frac{7}{8} \\
1 & 1 & 1 & 1 \\
1 & 1 & -1 & -1 \\
0 & 0 & 1 & -1
\end{array}\right) .
$$

According to [23], any function $y(\xi)$ that is integrable in the interval $[0,1)$ can be expanded into the Haar series :

$$
y(\xi)=\sum_{i=1}^{\infty} c_{i} h_{i}(\xi)
$$

where $c_{i}$ are the wavelet coefficients, which can be calculated by minimising the integral square error (see [17]). In the present article, the sum is limited by $2 \mathrm{M}$ terms. The discrete form of (17) with $2 M$ is

$$
y\left(\xi_{l}\right)=\sum_{i=1}^{2 M} c_{i} h_{i}\left(\xi_{l}\right)
$$

where $\xi_{l}(l=1,2, \ldots, 2 M)$ are the collocation points. The matrix form of (18) is

$$
y=c H,
$$

where $H$ is the Haar matrix, $c=\left(c_{i}\right)$ and $y=\left(y_{l}\right)$ are $2 M$ dimensional row vectors. The Haar wavelet coefficients can be found by:

$$
c=y H^{-1},
$$

where $H^{-1}$ is the inverse of the Haar matrix. Replacing $c$ into (17) with $i=1, \ldots, 2 M$, the wavelet approximation of function $y$ with the level of resolution $J$ can be obtained. The accuracy of the approximation is discussed in several articles [23,26,27]. Equation (20) is called the forward discrete transform, and (19) is called the inversed discrete transform. Since $H_{2 M \times 2 M}$ and $H_{2 M \times 2 M}^{-1}$ contain many zeros, the Haar transform is much faster than the Fourier transform [17].

In the present study, the Haar wavelet transform is applied to the first mode shape of the beam on the Pasternak foundation since it is the most informative [6].

\section{NUMERICAL EXAMPLES}

The procedure and identification of a single crack in the Euler-Bernoulli beam can be found in several research papers $[11,16,18]$. Taking into account the previous experience, the present section focuses on the Euler-Bernoulli beam placed on the Pasternak foundation $\left(G_{1}=10, G_{2}=2.5 \pi^{2}\right)$. One end of the beam is clamped, the other one is pinned. The ratio between the beam height and length is set to 0.1. The beam length is scaled to 1 .

\subsection{Quantification of two cracks}

Two cracks were induced at the arbitrary points along the beam. One crack was induced from 0.1 to 0.7 units from the left side of the beam $\left(L_{1}\right)$; the second crack was induced from 0.1 to 0.8 units from the first crack $\left(L_{2}\right)$ so that both cracks were in the range of 0.1 to 0.8 units. On practical grounds, the minimum and maximum values of crack depths $\left(D_{1}, D_{2}\right)$ were set between 0.01 and 0.5 (Fig. 2). 


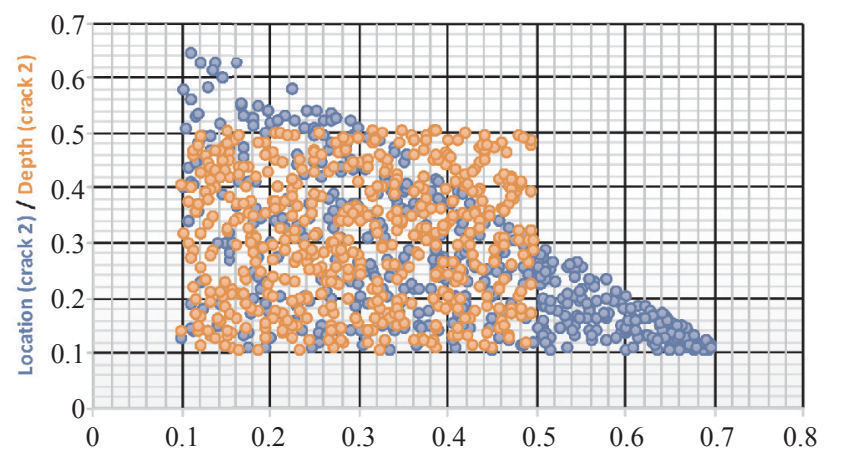

Fig. 2. Distribution of the crack characteristics in the dataset.

The dynamic response of the cracked beam (the first mode shape and the first eight dimensionless natural frequency parameters (DFPs)) was computed using the procedure described in [15]. In the first dataset, the records contained scaled characteristics of the cracks (location and depth) and the first eight DFPs. In the second set of data, each record contained scaled crack characteristics, and 16 Haar wavelet coefficients (HWCs). The coefficients were calculated using Eqs (17)-(20) and normalised. In total, each dataset contained 1230 patterns: 1110 records were used for training and 120 records were used for testing the predictive models.

The investigation on the ANN architecture and training functions showed that the most accurate predictions of crack quantification were made by a chain of four independent ensembles of the ANNs (the idea originated from [13]). Each ANN predicted only one parameter at a time: the location of the first crack, the location of the second crack, the severity of the first crack, and the severity of the second crack. The networks were trained by the Bayesian regularisation training function. The use of various gradient training algorithms (such as gradient descent with adaptive learning rate or momentum, conjugate gradient with Fletcher-Reeves or Powell-Beale or Polak-Ribiere updates) did not show accurate prediction results for crack quantification. Each one-hidden-layer feed forward ANN with back propagation had ten neurons in the hidden layer since the gradual increase in the hidden neurons from 10 to 150 with a step of ten neurons decreased the accuracy of the predictions. The differential transfer function in the hidden layer was Elliot symmetric sigmoid (elliotsig). The linear transfer function was used in the output layer (purelin); the positive linear transfer function (poslin) in the output layer did not provide promising results. The training of the ANNs was stopped when an acceptable level of error was achieved (MSE $=1 \mathrm{e}-4)$, or when the number of the iterations exceeded 10000 , or the number of the validation checks reached six. All the calculations were carried out using MatLab 2020a and MacBook Pro Dual-Core Intel i5 2.5GHz with an 8 GB memory.

Figure 3 shows the most accurate results (the correlation between the predicted and expected values, and the error histogram). They were obtained by the ensembles of the ANNs.

In particular, the mean square error (MSE) of the first crack depth was 1.1e-3 and of the second crack depth was 1.0e-3. The R-values were 9.515e-1 and 9.586e-1, respectively. The ANNs were provided with the first eight DFPs. The MSE of the first crack localisation was 2.1e-3 and the MSE of the distance between the two cracks was $1.9 \mathrm{e}-3$. The R-values were $9.553 \mathrm{e}-1$ and $9.677 \mathrm{e}-1$, respectively. In this case the feature vector contained the first eight HWCs out of 16.

Figure 4 shows the results (the correlation between the predicted and expected values, and the error histogram) obtained by the RFs. Specifically, the depths of the two cracks were predicted by two RFs with 50 trees in the forest trained independently. Each RF was provided with the same DFP-based dataset. The feature vector contained eight DFPs (six predictors without replacement). The MSE of the first crack depth was $6.3 \mathrm{e}-6$ and of the second crack depth was 5.9e-6. The R-values were 9.998e-1 and 9.998e-1, respectively. The locations of the cracks were predicted by the other two RFs with ten trees in each forest. The RFs were provided with the HWC-based dataset. The feature vector contained the first eight HWCs out 
(a)

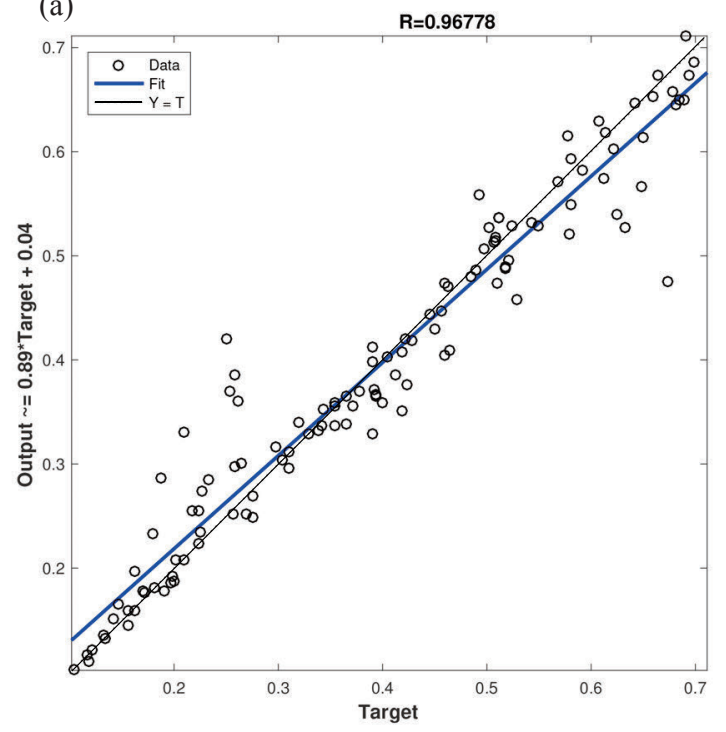

(c)

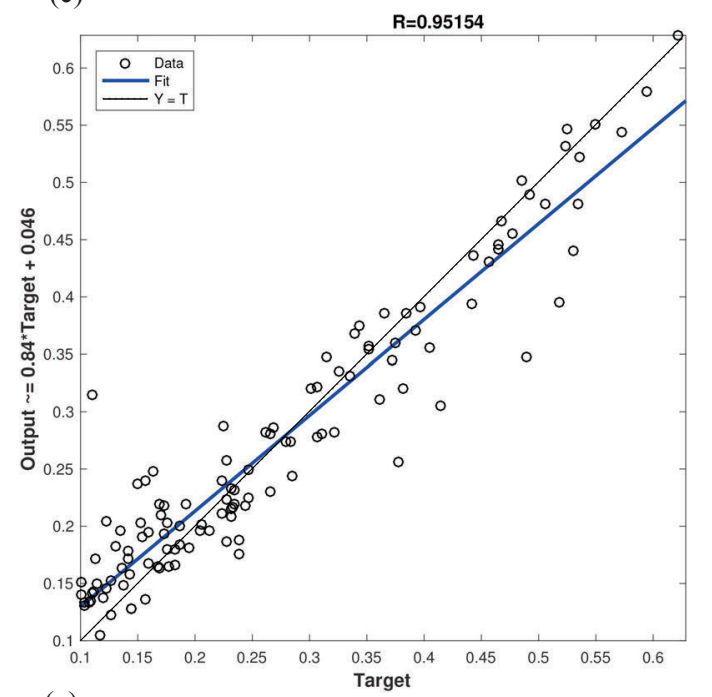

(e)

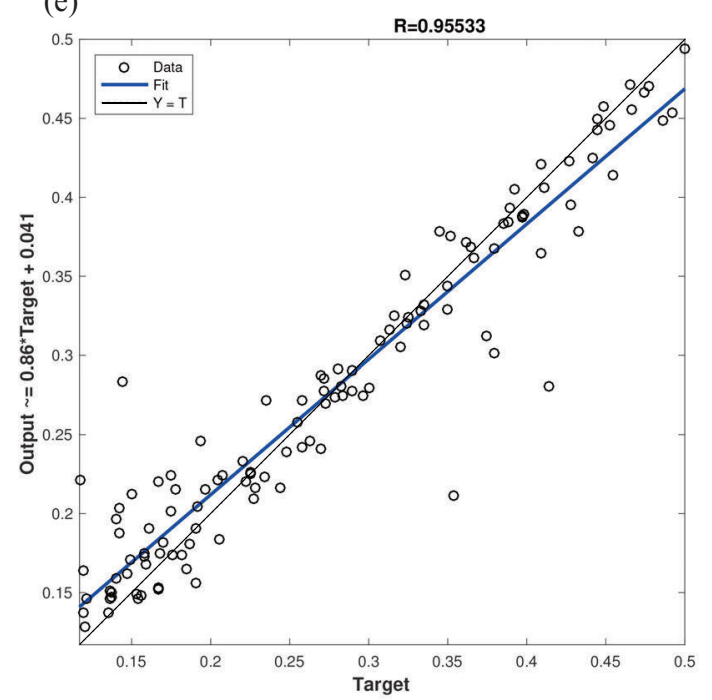

(b)
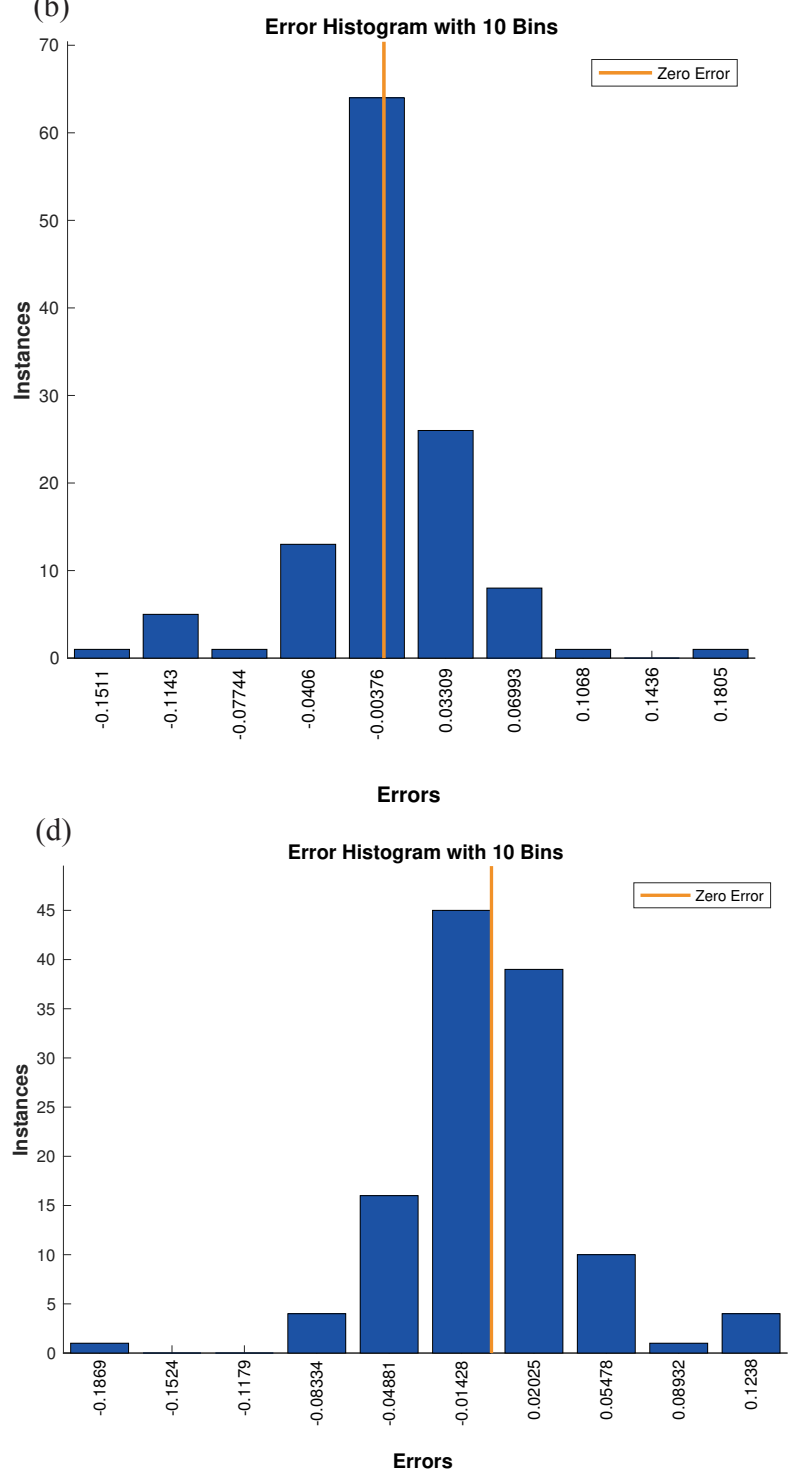

(f)

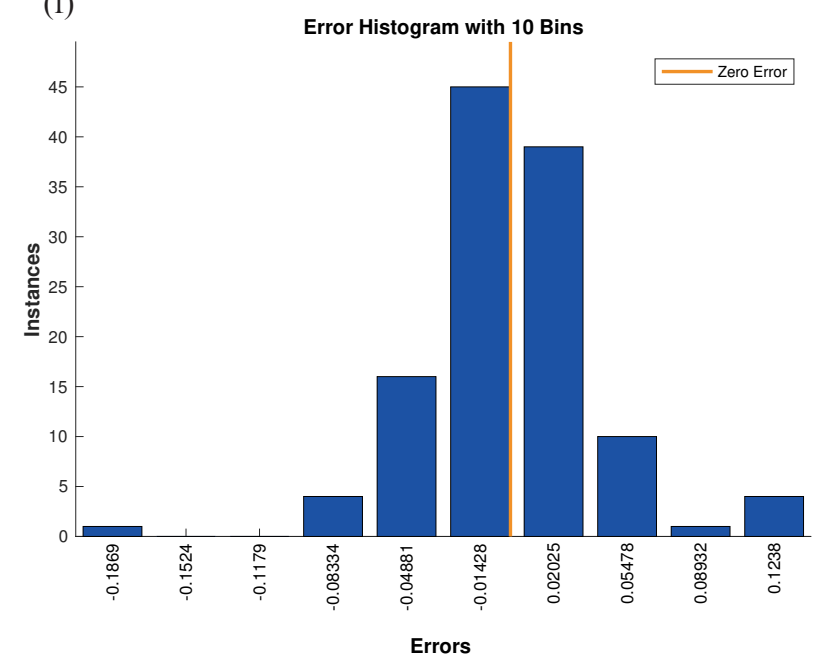

Fig. 3. Correlation and error distribution of the predicted cracks by the ensemble of the ANNs: (a)-(b) location from the left side of the beam; (c)-(d) distance between two cracks; (e)-(f) depth of the first crack; (g)-(h) depth of the second crack. (Continued on the next page.) 


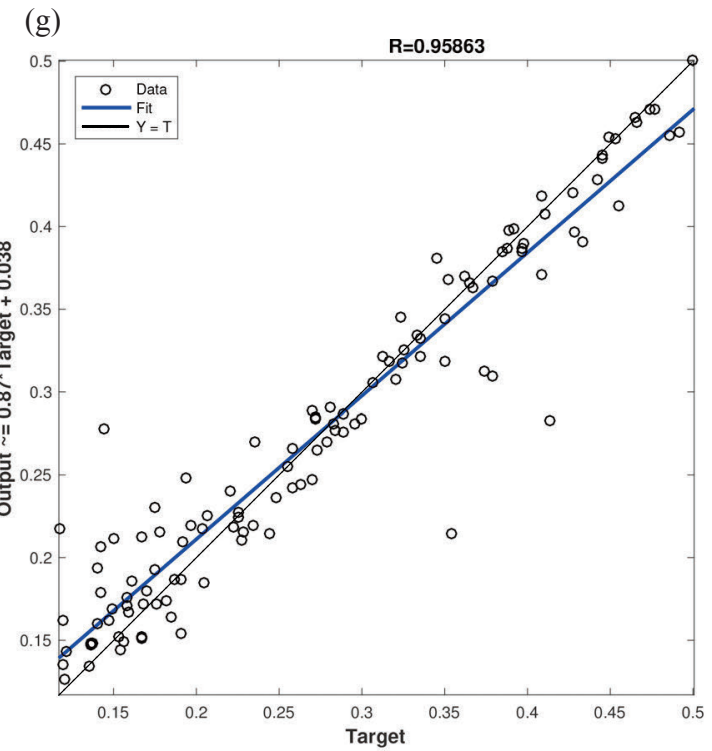

(h)

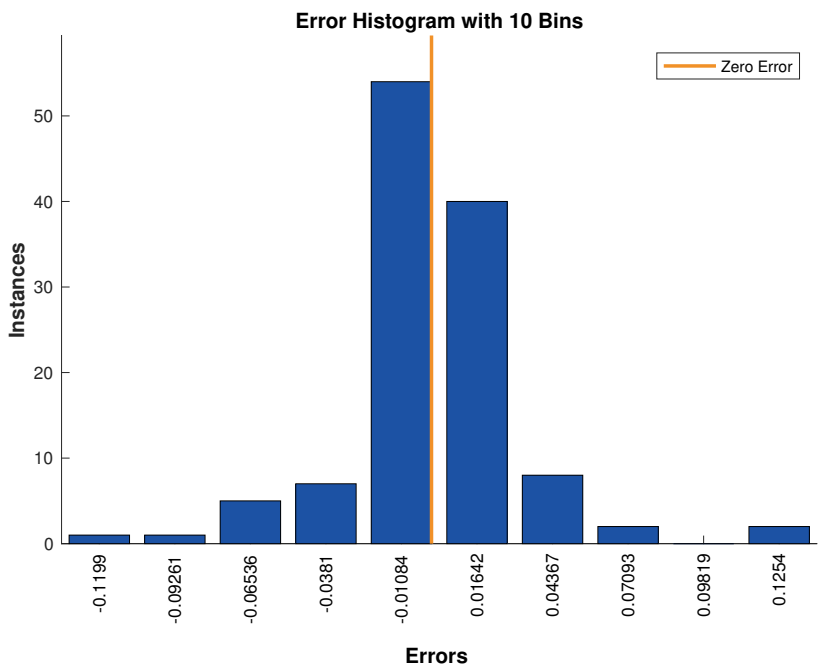

Fig. 3. Continued

of 16 (six predictors without replacement). The MSE of the first crack location was 2.4e-5 and the MSE of the distance between the two cracks was $2.1 \mathrm{e}-5$. The R-values were $9.997 \mathrm{e}-1$ and $9.997 \mathrm{e}-1$, respectively.

Comparing the results of the ANNs and the RFs, it was noted that the RFs slightly outperformed the ANNs. The observation could be explained by the fact that the RFs had fewer hyperparameters to tune. Also, it was noted that the training process was remarkably shorter in the case of the RFs than in the case of the ANNs.

\subsection{One crack or two cracks}

The proposed method of the modal data, Haar wavelets and machine learning examined in the previous subsection quantifies cracks accurately if the number of cracks in the beam is known in advance. In practice, the number of cracks in the beam is not known a priori. Therefore, the proposed method has to be supplemented with a classifier.

In the present research, the classifier was implemented in terms of the ANN or the RF. The architecture and the hyperparameters of the ANN were set the same as in the regression task on the crack quantification (Subsection 4.1). A one-hidden-layer feed forward network with back propagation had ten hidden neurons. The network was trained by the Bayesian regularisation training function. Elliot symmetric sigmoid transfer function was used in the hidden layer and the linear transfer function was used in the output layer. The RF had 50 trees.

The classifiers were examined using two datasets: the DFP-based dataset and the HWC-based dataset. Each dataset consisted of 2400 records: 1200 records of the beams with one crack and 1200 records of the beams with two cracks. Each dataset was split into the training and testing set in the ratio of 90 per cent and 10 per cent. The feature vector of the DFP-based dataset contained the first eight DFPs; the feature vector of the HWC-based dataset contained 16 HWCs transformed from the first mode shape.

The results of the classification are shown in the confusion matrix (Fig. 5). The matrix was the same in all four cases: classification by the ANN provided with DFPs or HWCs, and classification by the RF provided with DFPs or HWCs. High accuracy (F-score $=1.0$ ) could be explained by the fact that two cracks caused higher frequencies (the first NFP was around four units) than single cracks (the first NFP was around 20 units). 
(a)

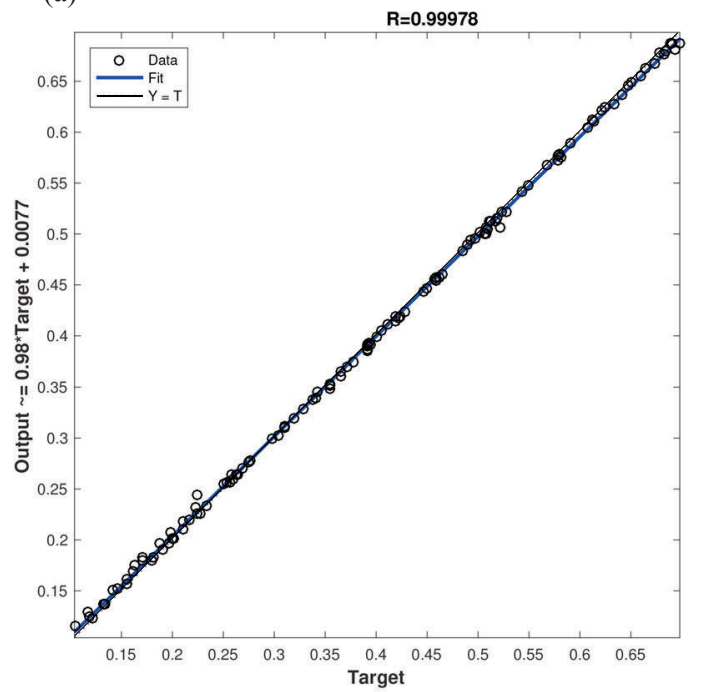

(c)

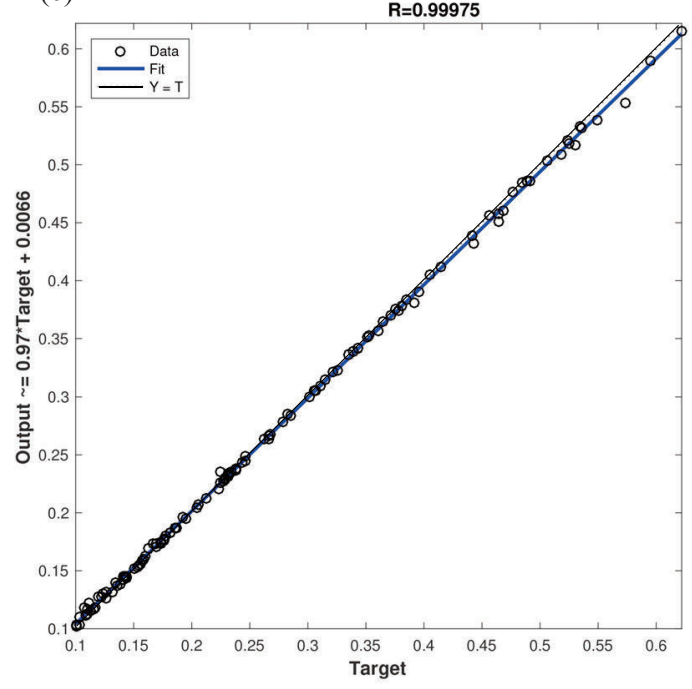

(e)

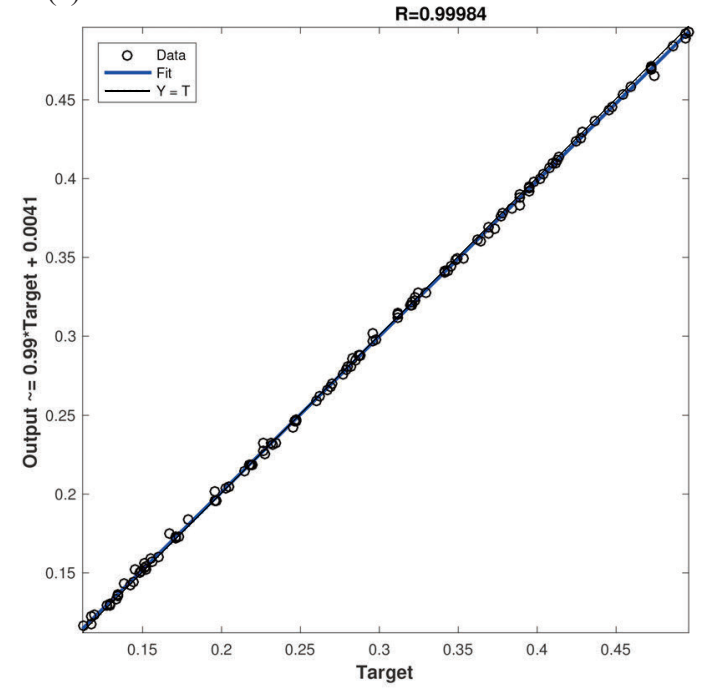

(b)

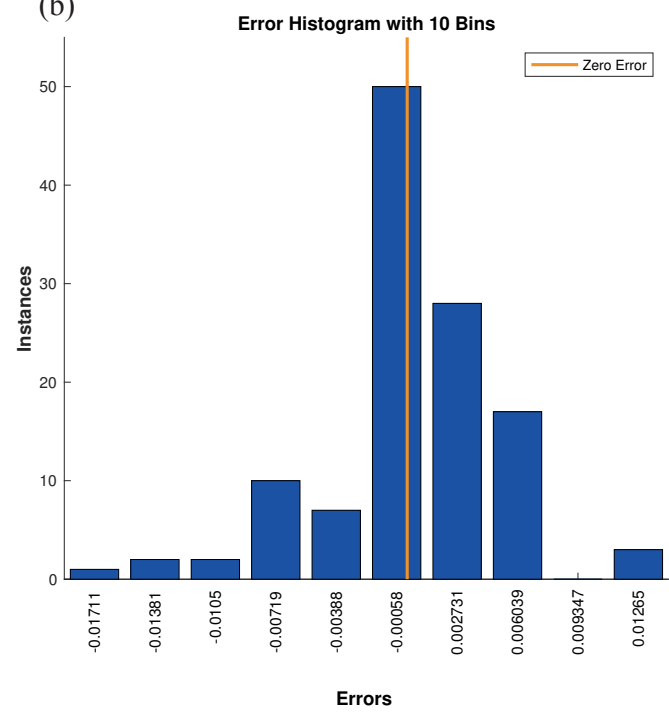

(d)
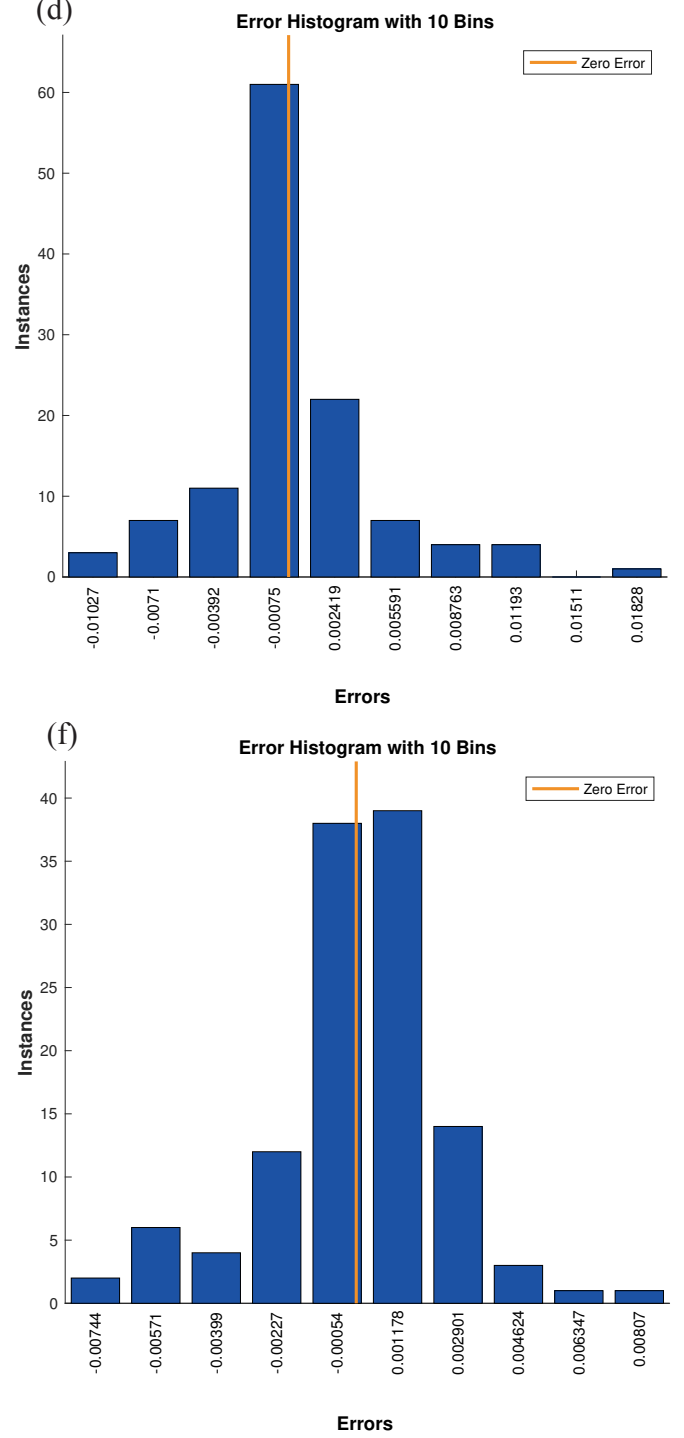

Fig. 4. Correlation and error distribution of the predicted cracks by the ensemble of the RFs: (a)-(b) location from the left side of the beam; (c)-(d) distance between two cracks; (e)-(f) depth of the first crack; (g)-(h) depth of the second crack. (Continued on the next page.) 
(g)

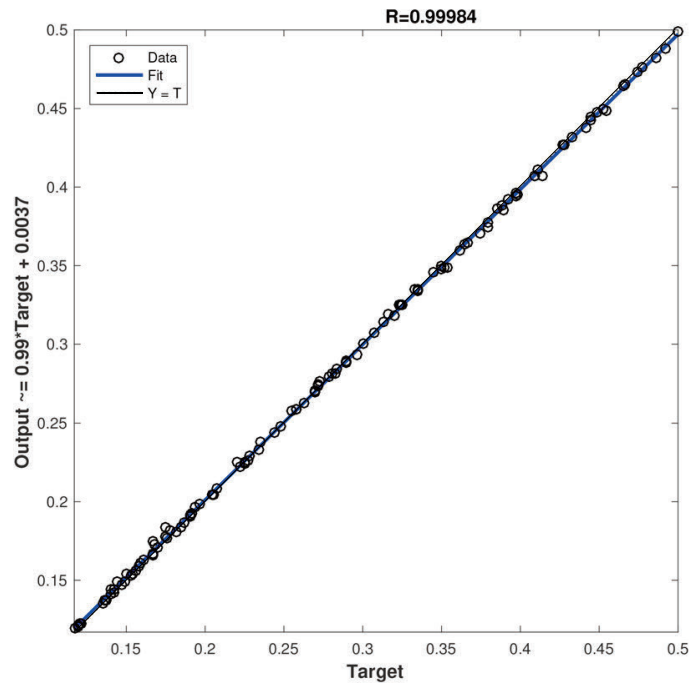

(h)

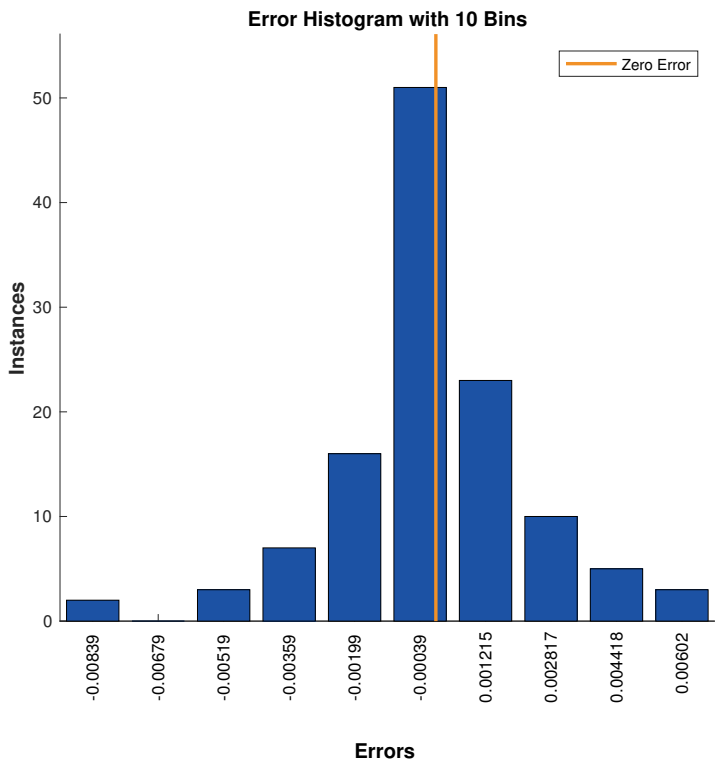

Fig. 4. Continued

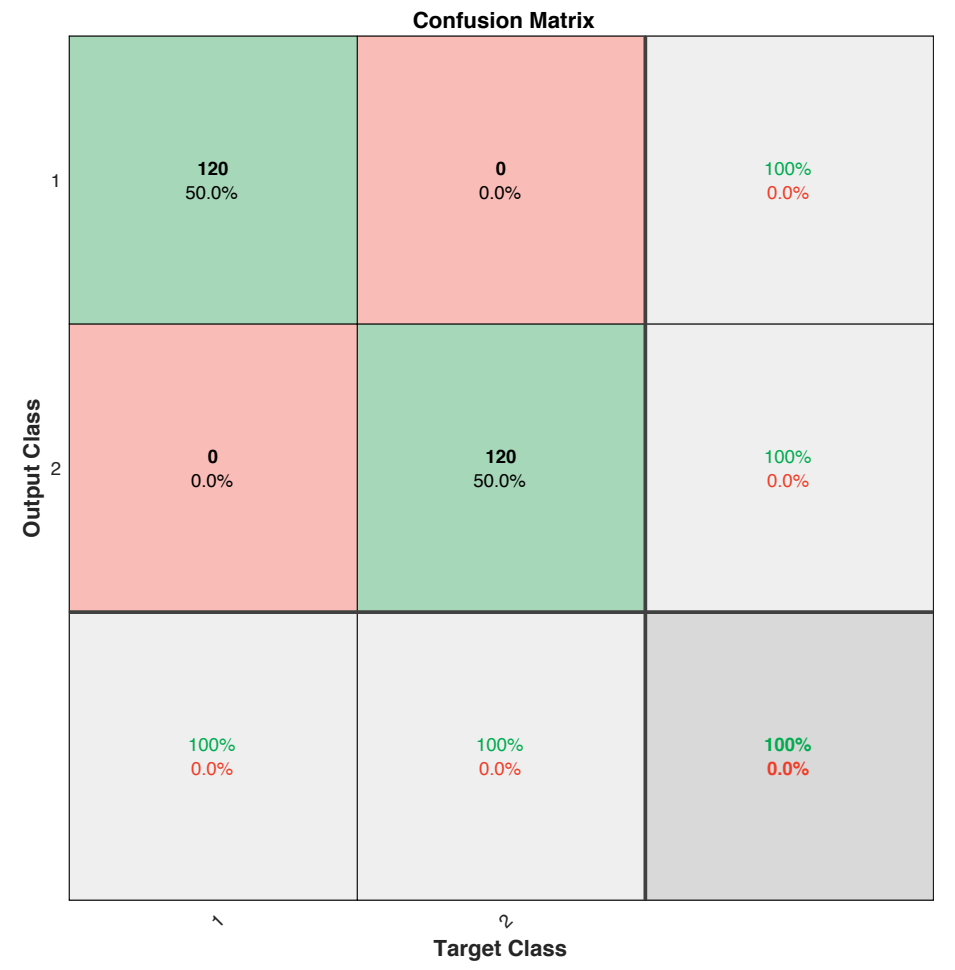

Fig. 5. Confusion matrix of the predicted and actual numbers of cracks in the beam. 


\section{CONCLUSIONS}

In the present research, the Euler-Bernoulli beam resting on the Pasternak foundation was investigated. The primary objective of the research was to find an efficient predictive model for crack identification and quantification. Among various machine learning methods, the feed forward back propagation ANNs and the RFs were used for their popularity and efficiency in other engineering disciplines. Another objective of the research was related to the datasets. Specifically, different feature vectors were investigated with the aim of finding an informative one. Two sets of data were calculated numerically. The first one contained the first eight DFPs; the other one - up to 16 HWCs derived from the first mode shape. The hypotheses were evaluated on the testing set (not shown to the predictive models in advance).

The results of crack quantification showed that the RFs slightly outperformed the ensemble of the ANNs. Notably, the RFs had fewer hyperparameters to tune and the training process was remarkably shorter than in the case of the ANNs.

Analysing the results of the predictions, it was detected that the depth of cracks was more difficult to predict accurately than the location. The dataset of eight DFPs produced more accurate predictions of the crack depths but not of the crack locations. The hypothesis on the sensitivity of the HWCs towards the crack localisation was decisively confirmed; however, the Haar wavelet transform method could not follow the severity of the crack.

The classification task on the number of cracks in the beam was solved by the ANN and the RF. The machine learning methods were provided either with the DFPs or HWCs. Disregarding the nature of the features in the patterns, both machine learning methods classified the beams accurately (F-score $=1.0$ ). High accuracy was explained by the unique values of the features.

In the present research, the problems arising from the arrangement of experiments and measured modal data cleansing (filter noise, spike removal, removal of outliers, treatment of missing data) were not taken into account. In order to apply the proposed numerical approach not only to the modelling or simulations of beam-like structure but also in practice, the approach has to be validated by the experiment and experimental data.

Furthermore, in order to evaluate the flexibility of the proposed approach of the machine learning, modal data and the Haar wavelets, it is recommended that the approach be validated on other structural elements (I-beams, T-beams, rods, ties, shells, plates), material constitutive models (elastic-plastic or plastic models), and types of damage (breathing cracks, subsurface cracks, transverse cracks, necks, debonding, faults, fractures).

The presented methods can be extended for analysing other important engineering elements, e.g. delaminated beams, cracked Timoshenko beams, buckling beams, cracked functionally graded beams.

\section{ACKNOWLEDGEMENTS}

The research was supported by Institutional Research Funding project IUT34-4. The publication costs of this article were covered by the Estonian Academy of Sciences.

\section{REFERENCES}

1. Addison, P. S. The Illustrated Wavelet Transform Handbook. Institute of Physics Publishing, Bristol and Philadelphia, 2002.

2. Ajayan, A. Higher mode natural frequencies of stepped beam using spectral finite elements. Master's thesis. Rourkela National Institute of Technology, India, 2013.

3. Ansari, R., Gholami, R., Hosseini, K. and Sahmani, S. A sixth-order compact finite difference method for vibrational analysis of nanobeams embedded in an elastic medium based on nonlocal beam theory. Math. Comput. Model., 2011, 54(11), $2577-2586$. http://www.sciencedirect.com/science/article/pii/S0895717711003712

4. Aziz, I. and Amin, R. Numerical solution of a class of delay differential and delay partial differential equations via Haar wavelet. Appl. Math. Model., 2016, 40(23-24), 10286-10299. 
5. Aziz, I., Siraj-ul-Islam and Šarler, B. Wavelets collocation methods for the numerical solution of elliptic BV problems. Appl. Math. Model., 2013, 37(3), 676-694.

6. Cao, M., Ye, L., Zhou, L. M., Su, Z. and Bai, R. Sensitivity of fundamental mode shape and static deflection for damage identification in cantilever beams. Mech. Syst. Signal Process., 2011, 25(2), 630-643.

7. Celep, Z., Guler, K. and Demir, F. Response of a completely free beam on a tensionless Pasternak foundation subjected to dynamic load. Struct. Eng. Mech., 2011, 37(1), 61-77.

8. Chen, B., Lin, B., Zhao, X., Zhu, W., Yang, Y. and Li, Y. Closed-form solutions for forced vibrations of a cracked double-beam system interconnected by a viscoelastic layer resting on Winkler-Pasternak elastic foundation. Thin-Walled Struct., 2021, 163, 107688. https://www.sciencedirect.com/science/article/pii/S0263823121001725

9. Dimarogonas, A. D., Paipetis, S. A. and Chondros, T. G. Analytical Methods in Rotor Dynamics. Springer Netherlands, 2013.

10. Elishakoff, I. Some unexpected results in vibration of non-homogeneous beams on elastic foundation. Chaos Solit. Fractals, 2001, 12(12), 2177-2218. http://www.sciencedirect.com/science/article/pii/S0960077900001235

11. Feklistova, L. and Hein, H. Crack localization in Euler-Bernoulli beams. In Proceedings of the 2nd International Conference Optimization and Analysis of Structures, Tartu, Estonia, August 25-27, 2013 (Lellep, J. and Puman, E., eds). University of Tartu Press, 35-38.

12. Hadjileontiadis, L. J., Douka, E. and Trochidis, A. Fractal dimension analysis for crack identification in beam structures. Mech . Syst. Signal Process., 2005, 19(3), 659-674. www.sciencedirect.com/science/article/pii/S0888327004000330

13. Hakim, S. J. S., Razak, H. A. and Ravanfar, S. A. Fault diagnosis on beam-like structures from modal parameters using artificial neural networks. Measurement, 2015, 76, 45-61. https://www.scopus.com/inward/record.uri?eid=2-s2.084941363651\&doi=10.1016\%2fj.measurement.2015.08.021\&partnerID=40\&md5=b663b27c3930d93d802a13721856bc9e

14. Hakim, S. J. S., Razak, H. A., Ravanfar, S. A. and Mohammadhassani, M. Structural damage detection using soft computing method. In Structural Health Monitoring, Vol. 5 (Wicks, A., ed.). Springer, Cham, 2014, 143-151. https://doi.org/10.1007/9783-319-04570-2 16

15. Hein, H. and Feklistova, L. Free vibrations of non-uniform and axially functionally graded beams using Haar wavelets. Eng. Struct., 2011, 33(12), 3696-3701. http://www.sciencedirect.com/science/article/pii/S0141029611003208

16. Hein, H. and Jaanuska, L. Comparison of machine learning methods for crack localization. Acta et Comment. Univ. Tartu. de Math., 2019, 23(1), 125-142.

17. Hsiao, C.-H. and Wang, W.-J. State analysis of time-varying singular nonlinear systems via Haar wavelets. Math. Comput. Simul., 1999, 51(1-2), 91-100. http://www.sciencedirect.com/science/article/pii/S037847549900107X

18. Jaanuska, L. and Hein, H. Crack identification in beams using Haar wavelets and machine learning methods. Int. J. Mech., 2016, 10, 281-287.

19. Jayawardhana, M., Zhu, X., Liyanapathirana, R. and Gunawardana, U. Statistical damage sensitive feature for structural damage detection using AR model coefficients. Adv. Struct. Eng., 2015, 18(10), 1551-1562.

20. Karnovsky, I. A. and Lebed, O. I. Formulas for Structural Dynamics. McGraw-Hill, New York, NY, 2001.

21. Konar, P. and Chattopadhyay, P. Bearing fault detection of induction motor using wavelet and Support Vector Machines (SVMs). Appl. Soft Comput., 2011, 11(6), 4203-4211. http://www.sciencedirect.com/science/article/pii/S1568494611001104

22. Lepik, Ü. Numerical solution of differential equations using Haar wavelets. Math. Comput. Simul., 2005, 68(2), $127-143$. http://www.sciencedirect.com/science/article/pii/S0378475404002757

23. Lepik, Ü. and Hein, H. Haar Wavelets: With Applications. Springer International Publishing Switzerland, 2014.

24. Li, J. and Hua, H. Spectral finite element analysis of elastically connected double-beam systems. Finite Elem. Anal. Des., 2007, 43(15), 1155-1168.

25. Mahmoud, M. A. and Kiefa, M. A. A. Neural network solution of the inverse vibration problem. NDT E Int., 1999, 32(2), 91-99. http://www.sciencedirect.com/science/article/pii/S0963869598000267

26. Majak, J., Pohlak, M., Karjust, K., Eerme, M., Kurnitski, J. and Shvartsman, B. S. New higher order Haar wavelet method: application to FMG structures. Compos. Struct., 2018, 201, 72-78.

27. Majak, J., Shvartsman, B. S., Kirs, M., Pohlak, M. and Herranen, H. Convergence theorem for the Haar wavelet based discretization method. Compos. Struct., 2015, 126, 227-232.

28. Matbuly, M. S., Ragb, O. and Nassar, M. Natural frequencies of a functionally graded cracked beam using the differential quadrature method. Appl. Math. Comput., 2009, 215, 2307-2316.

29. Misiti, M., Misiti, Y., Oppenheim, G. and Poggi, J.-M. Wavelet Toolbox User's Guide. The MathWorks, Natick, MA, 1997.

30. Misiti, M., Misiti, Y., Oppenheim, G. and Poggi, J.-M. (eds). Wavelets and their Applications. Wiley, 2013.

31. Ndambi, J.-M., Vantomme, J. and Harri, K. Damage assessment in reinforced concrete beams using eigenfrequencies and mode shape derivatives. Eng. Struct., 2002, 24(4), 501-515.

32. Ostachowicz, W. and Güemes, J. A. New Trends in Structural Health Monitoring. Springer, Vienna, 2013.

33. Özdemir, Y. I. Development of a higher order finite element on a Winkler foundation. Finite Elem. Anal. Des., 2012, 48, 14001408.

34. Pervaiz, N. and Aziz, I. Haar wavelet approximation for the solution of cubic nonlinear Schrodinger equations. Phys. A: Stat. Mech. Appl., 2020, 545, 123738.

35. Quek, S.-T., Wang, Q., Zhang, L. and Ang, K.-K. Sensitivity analysis of crack detection in beams by wavelet technique. Int. J. Mech. Sci., 2001, 43(12), 2899-2910. http://www.sciencedirect.com/science/article/pii/S0020740301000649 
36. Rizos, P. F., Aspragathos, N. and Dimarogonas, A. Identification of crack location and magnitude in a cantilever beam from the vibration modes. J. Sound Vib., 1990, 138(3), 381-388. http://www.sciencedirect.com/science/article/pii/0022460X90905930

37. De Rosa, M. A. and Maurizi, M. J. Dynamic analysis of multistep piles on Pasternak soil subjected to axial tip forces. J. Sound Vib., 1999, 219(5), 771-783.

38. Rucka, M. and Wilde, K. Application of continuous wavelet transform in vibration based damage detection method for beams and plates. J. Sound Vib., 2006, 297(3-5), 536-550. http://www.sciencedirect.com/science/article/pii/S0022460X06003336

39. Rucka, M. and Wilde, K. Crack identification using wavelets on experimental static deflection profiles. Eng. Struct., 2006, 28(2), 279-288. http://www.sciencedirect.com/science/article/pii/S0141029605002956

40. Shifrin, E. I. and Ruotolo, R. Natural frequencies of a beam with an arbitrary number of cracks. J. Sound Vib., 1999, 222(3), 409-423.

41. Silva, T., Maia, N., Roque, A. and Travassos, J. Identification of elastic support properties on a Bernoulli-Euler beam. In Proceedings of the 27th International Modal Analysis Conference, Orlando, FL, USA, February 9-12, 2009. Society for Experimental Mechanics, 2009, 4, 1848-1860.

42. Skrinar, M. and Lutar, B. A three-node beam finite element for transversely cracked slender beams on Winkler's foundation. Comput. Mater. Sci., 2012, 64, 260-264.

43. Ubertini, F., Comanducci, G. and Cavalagli, N. Vibration-based structural health monitoring of a historic bell-tower using outputonly measurements and multivariate statistical analysis. Struct. Health Monit., 2016, 15(4), 438-457.

44. Wang, Y. Damage assessment in asymmetric buildings using vibration techniques. PhD thesis. Queensland University of Technology, Australia, 2018.

45. Worden, K., Staszewski, W. J. and Hensman, J. J. Natural computing for mechanical systems research: A tutorial overview. Mech. Syst. Signal Process., 2011, 25(1), 4-111. http://www.sciencedirect.com/science/article/pii/S0888327010002499

46. Wu, Z. S. and Adewuyi, A. P. Vibration-based structural health monitoring technique using statistical features for data stability assessment and damage localization. Sensors and Smart Structures Technologies for Civil, Mechanical, and Aerospace Systems, 2009, 729233.

47. Yan, Y. J., Cheng, L., Wu, Z. Y. and Yam, L. Development in vibration-based structural damage detection technique. Mech. Syst. Signal Process., 2007, 21, 2198-2211.

\title{
Pragude määramine võnkuvates Pasternaki alusel talades, rakendades masinõppe meetodeid ja Haari lainikuid
}

\author{
Helle Hein ja Ljubov Jaanuska
}

Eksperimentaalsetes uuringutes on tuvastatud, et praod võnkuvates talades tekitavad muutusi võnkumise modaalsetes omadustes (nt vabavõnkumise sagedustes ja moodides). Selles artiklis käsitletakse pragude tuvastamise, lokaliseerimise ja raskusastme määramist võnkumise modaalsete omaduste kaudu. Konkreetse ülesandena vaadeldi ühe ja kahe praoga Pasternaki alusel võnkuvat Euler-Bernoulli tala. Pragude arvu, asukoha ja raskusastme määramiseks kasutati tehisnärvivõrke ning tingimuslikke otsustuspuid ehk juhumetsi. Andmekogumite genereerimiseks lahendati võnkumise võrrand ja tulemusi töödeldi Haari lainikute abil. Numbrilised eksperimendid näitasid, et omavõnkumiste sageduste, moodide, Haari lainikute ja masinõppe meetodite kombineeritud lähenemine võimaldab täpselt määrata pragude arvu, asukohta ning raskusastet. 